Ihab Kaddoura, Kai Nagel

\title{
Simultaneous internalization of traffic congestion and noise exposure costs
}

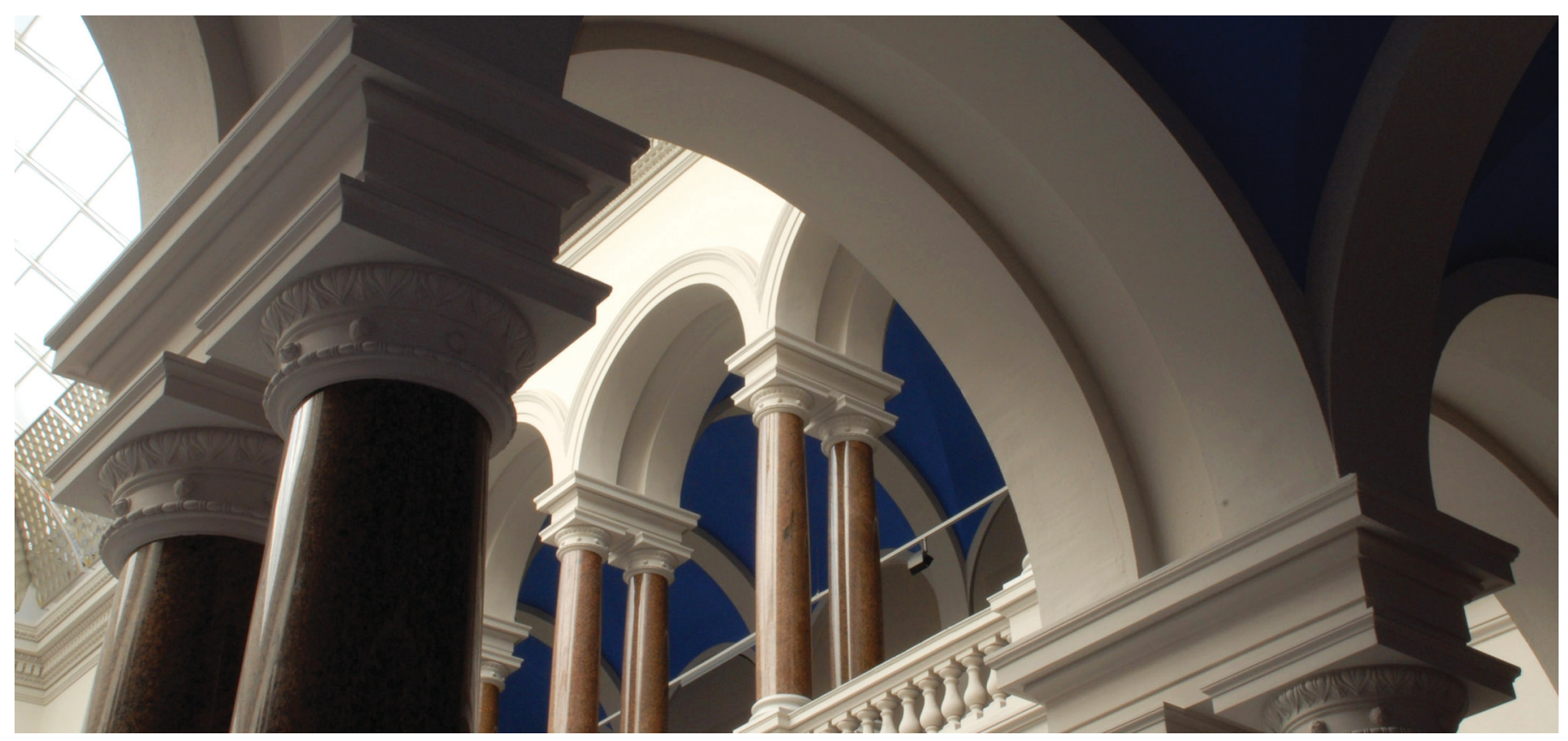

This is a post-peer-review, pre-copyedit version of an article published in Transportation. The final authenticated version is available online at: http://dx.doi.org/10.1007/s11116-017-9776-0.

Kaddoura, I.; Nagel, K. (2017). Simultaneous internalization of traffic congestion and noise exposure costs. Transportation, 45(5), 1579-1600. https://doi.org/10.1007/s11116-017-9776-0 


\title{
Simultaneous optimization of traffic congestion and noise exposures
}

\author{
Ihab Kaddoura*, Kai Nagel \\ Technische Universität Berlin \\ Transport Systems Planning and Transport Telematics \\ Salzufer 17-19; 10587 Berlin; Germany \\ * Corresponding author \\ e-mail: kaddoura@vsp.tu-berlin.de \\ tel.: +493031478 793 \\ fax.: +493031426269
}

February 10, 2016

\begin{abstract}
This study elaborates on the interrelation of external effects. For congestion and noise, single objective optimization is compared with multiple objective optimization. The optimization methodology follows an iterative market-based approach. An agentbased simulation framework is used to dynamically compute and internalize userspecific external congestion effects and noise exposures. The innovative optimization methodology is applied to the real-world case study of the Greater Berlin area. The results reveal a negative correlation between congestion and noise. Nevertheless, the multiple objective optimization results in a simultaneous reduction in congestion and noise. During peak times, congestion is the more relevant external effect, whereas, during the evening, night and morning, noise is the more relevant externality. Thus, a key element for policy making is to follow a dynamic approach, i.e. to temporally change the incentives. During peak times, congestion should be reduced by shifting transport users from the inner-city motorway to smaller roads, whereas, during offpeak times, noise should be reduced by concentrating traffic flows along main roads, i.e. inner-city motorways.
\end{abstract}

Keywords: Road Traffic Noise, Traffic Congestion, Internalization, Optimal Pricing, Dynamic Tolling, Activity-based Transport Modeling 


\section{Introduction and problem statement}

Transport users do not only invest their own time and money, but impose so-called external costs on others, such as congestion, noise, air pollution, or accidents. If the users had to compensate for their external damages, they might behave differently, e.g. by using other routes, other time slots, switching to environmentally friendlier vehicles or modes, or travel less. The economic theory states that correct prices yield an optimal use of transport resources. However, due to the existence of external effects, prices only reflect parts of the full cost. Consequently, the wrong incentives are given which results in a typically too extensive usage of transport resources yielding welfare losses. Following the concept introduced by Pigou (1920), the social welfare optimum can be achieved by correcting the costs payed by the transport users according to the marginal external cost. Thus, external costs are internalized and prices reflect full cost. Hence, pricing can be understood as a decentralized (or market-based) instrument to change individual travel decisions towards an overall improved transport system (see e.g. Maibach et al., 2008; Small and Verhoef, 2007).

Several studies indicate that during peak times, congestion causes the largest part of all transport related external costs (see e.g. Maibach et al., 2008; de Borger et al., 1996; Small and Verhoef, 2007, Parry and Small, 2009, p. 103). In particular, for heavy goods vehicles (HGV) and during night times, noise is found to be a very important contribution to the total external costs (Maibach et al. 2008; Nash, 2003). In this study, the focus is placed on traffic congestion and noise exposures which both differ in many respects. Increased travel times due to traffic congestion mainly affect individuals within the transport system, i.e. the following road users. In contrast, traffic noise primarily affects individuals outside the transport system, for example local residents. Furthermore, traffic congestion and noise differ significantly in their cost structure. Marginal congestion cost are above average congestion cost (Maibach et al., 2008; Korzhenevych et al., 2014). In contrast, marginal noise cost are below average noise cost which is explained by the logarithmic characteristic of noise, i.e. that the impact of an additional vehicle is smaller for large traffic volumes compared to small traffic volumes (FGSV, 1992; Maibach et al., 2008). Several studies indicate that external effects such as traffic congestion, noise, air pollution and accidents are interrelated with each other (see e.g. Calthrop and Proost, 1998; Barth and Boriboon- 
somsin, 2009, Ghafghazi and Hatzopoulou, 2014). That is, reducing one externality may increase or decrease other external effects. Noise computation models typically account for a road-specific free speed level in that a higher speed level increases the noise level (see e.g. FGSV, 1992). Makarewicz and Galuszka (2011) address the prediction of road traffic noise based on the speed-flow diagram. The authors find that traffic congestion and noise are inversely related, i.e. that a reduced speed level due to increased traffic congestion reduces the annual average sound level. The interrelation between speed level and air pollution is found to be "U"-shaped, with lower speeds and higher speeds yielding higher emissions than average speeds (Barth and Boriboonsomsin, 2009, Wismans et al., 2011; Kickhöfer et al. 2013). For the relation between congestion and accident costs, on the one hand, the number of interactions (and possible collisions) increase with the number of vehicles. On the other hand, for high traffic volumes, the speed level decreases because of congestion, which may lead to less severe accidents and decreasing accident costs (Shefer and Rietveld, 1997: High Level Group on Transport Infrastructure Charging, 1999: Maibach et al., 2008). Noland et al. (2008) analyze the impact of the London congestion charge on road casualties. The authors identify an increase in motorcycle casualties which is explained by the incentive to use motorcycles in order to avoid the congestion charge. However, the authors do not find a significant change in road casualties. Also, the increase in speed levels is found to have no effect on the severity of accidents. In several studies, the overall benefits are analyzed by measuring changes in congestion costs as well as other external costs for different transport policies (Beamon and Griffin, 1999; Daniel and Bekka, 2000; Proost and van Dender, 2001; Beevers and Carslaw, 2005, Percoco, 2014, 2015). Wismans et al. (2011) separately optimize single external effects and measure the impact on other externalities. The authors find congestion and air pollution to be positively correlated, whereas, congestion and air pollution are negatively correlated with noise and accidents. The interrelation of external effects makes it difficult for transport planners to employ the right policy. Ideally, a transport policy should simultaneously reduce all external costs which, however, may not be easy to achieve. In particular, the reduction of one external effect may increase another external effect. This inverse relationship between different external effects puts policy makers in a dilemma. A combined optimization approach in which several external effects are simultaneously minimized provides a way out and may help to resolve the trade-off between different external effects. In a few recent studies, 
external effects are simultaneously optimized for a simplified network using analytical methods, see for example Chen and Yang (2012) and Wang et al. (2014) who minimize the combined external costs of congestion and air pollutants or Verhoef and Rouwendal (2003) who minimize congestion and accident costs. In Shepherd (2008), a single link model is used to compute optimal tolls for simple and more complex $\mathrm{CO}_{2}$ and accident models. The author finds the complexity of the external cost model to have a significant impact on the optimal toll level. Because of their rather simplified nature, most analytical approaches are less appropriate to handle complex real-world networks or a more sophisticated representation of the transport demand side, for example multiple origin-destination points, non-deterministic behavior, complex user reactions, or user-user interactions such as dynamic congestion with spill-back. In contrast, Agarwal and Kickhöfer (2015) use an agent-based simulation framework to simultaneously optimize congestion and air pollution levels for a complex real-world scenario of the Munich metropolitan area. The authors find congestion and air pollution emissions to be positively correlated since the internalization of one external effect also reduces the other one.

This study aims to investigate the interrelation of congestion and noise in order to implement effective policies that control both congestion and noise. The inverse relation between congestion and noise raises the question if or how it is possible to simultaneously reduce both externalities by means of intelligent traffic management. Similar to Agarwal and Kickhöfer (2015) who looked at congestion and air pollution, the present study applies an agent-based simulation approach which simultaneously optimizes congestion levels and road traffic noise exposures. A market-based optimization approach is applied (see Sec. 2.1 which combines two external cost pricing tools, first a congestion internalization tool which accounts for dynamic queueing and heterogenous users (Kaddoura, 2015; Kaddoura and Nagel, 2016b, see Sec. 2.3 and, second, a marginal user-specific noise exposure pricing tool in which noise levels and population densities are dynamically computed (Kaddoura and Nagel, 2016a, see Sec. 2.4. The innovative optimization approach is applied to a real-world case study of the Greater Berlin area (see Sec. 3). Three simulation experiments are carried out which are analyzed with regard to the changes in travel behavior, congestion level, noise impact and overall system welfare (see Sec. 4). 


\section{Optimization methodology}

\subsection{General approach}

The proposed optimization methodology makes use of the market mechanism and follows the Pigouvian taxation principle. First, user-specific and local tolls are dynamically set according to the level of the external costs. Second, the transport users are enabled to adjust their travel behavior to avoid toll payments. Since the toll payments correspond to the external costs and the avoidance costs are taken into account by each transport user, the system changes towards a higher efficiency. The proposed optimization approach uses the open-source transport model MATSim ${ }^{1}$ to compute the external cost and to simulate the market mechanism, i.e. the changes in travel demand as a response to the external cost toll payments (see Sec. 2.2). In this study, the external costs are assumed to be composed of two cost components only, namely traffic congestion, i.e. delays imposed on other transport users (see Sec. 2.3), and noise damages, i.e. population exposures to traffic noise (see Sec. 2.4). However, the market-based optimization methodology allows to easily add further cost components.

\subsection{Transport Simulation Framework MATSim}

MATSim is an activity-based transport simulation where traffic is the result of spatially separated activities. The demand for transport is modeled as agents that have an individual mental and physical behavior. Initially, each agent's behavior has to provided by means of a travel plan which describes the daily activities (e.g. home-work-leisure-home) as well as the transport modes and activity end times. Applying an evolutionary iterative approach, the demand side adapts to the supply side and the initial behavior is modified. In each iteration, (1) the plans are executed (Traffic flow simulation), (2) evaluated (Evaluation) and (3) new plans are generated (Learning).

1. Traffic Flow Simulation All agents simultaneously execute their travel plans. Thereby, they interact in the physical environment. The vehicles are moved along road segments (links) applying a queue model Gawron (1998). Each link is considered as a First In First Out queue with the following attributes: a free speed travel

\footnotetext{
${ }^{1}$ Multi-Agent Transport Simulation, see www . matsim.org
} 
time, a flow capacity $c_{\text {flow, }}$, and a storage capacity (causing spill-back). Individual movements of agents can be aggregated to flows that are found to be consistent with the fundamental diagram (see e.g. Agarwal et al., 2015).

2. Evaluation Each executed plan is scored based on predefined behavioral parameters. A plan's score is typically composed of two parts, the trip related travel cost (e.g. travel time, monetary payments) and the utility gained from activity performing (see Charypar and Nagel, 2005).

3. Learning In every iteration, the agents choose a plan to be executed in the next iteration following a multinomial logit model. However, some agents generate new plans by making a copy an existing plan and modifying parts of the plan, for example the transport route (sequence of links the agent is taking to travel from one activity location to another one).

A repetition of the above described iteration allows the agents to improve and obtain plausible travel plans, and the simulation outcome stabilizes. Assuming each agent's travel plans to represent valid choice sets, the system state is considered as an approximate stochastic user equilibrium (Nagel and Flötteröd, 2012). Further details of the applied simulation framework are for example described in Raney and Nagel (2006).

\subsection{Congestion pricing}

In this study, external congestion effects are computed applying the methodology described in Kaddoura and Kickhöfer (2014) and Kaddoura (2015). The computation of external congestion effects is directly linked to the queue model described in Sec. 2.2 (Traffic Flow Simulation). Whenever an agent is delayed, the causing agents in the queue ahead are identified. The delay is converted into monetary units accounting for the delayed transport user's value of travel time savings. Thereby, the pricing approach considers model-inherent heterogeneous values of travel time savings (see Kaddoura and Nagel, 2016b). Based on the delay costs imposed on other travelers, the causing agents have to pay a toll. Hence, external congestion costs are internalized and transport users are enabled to change their travel behavior in order to avoid these tolls (see Sec. 2.1). 


\subsection{Noise exposure pricing}

In this study, noise damages are internalized applying the marginal cost approach presented in Kaddoura and Nagel (2016a). The computation of noise damages is mainly based on the German RLS-90 approach ('Richtlinien für den Lärmschutz an Straßen', FGSV, 1992 ) applying the approach 'lange, gerade Fahrstreifen' ('long, straight lanes'). For each time interval, noise emissions are calculated on the basis of the traffic flow, the HGV share and the speed level. Noise immissions are calculated for a predefined set of receiver points accounting for the noise emissions at the surrounding road segments. Each individuals' daily activities (locations and activity start and end times) are tracked and mapped to the receiver points. Both, the noise immissions and demand activities are required to compute noise exposures. The conversion into monetary units follows the threshold-based German EWS approach ('Empfehlungen für Wirtschaftlichkeitsuntersuchungen an Straßen' FGSV, 1997). Noise exposure costs are computed as

$$
C_{j, t}= \begin{cases}c^{T} \cdot N_{j, t} \cdot 2^{0.1 \cdot\left(I_{j, t}-I_{t}^{\min }\right)} & I_{j, t} \geq I_{t}^{\min } \\ 0 & I_{j, t}<I_{t}^{\min }\end{cases}
$$

where $C_{j, t}$ is the noise damage costs per receiver point $j$ and time interval $t ; N_{j, t}$ denotes the number of exposed individuals; $I_{j, t}$ is the noise immission level in $\mathrm{dB}(\mathrm{A}) ; I_{t}^{\text {min }}$ is the

threshold immission leve? $c^{T}$ is the cost rate computed as $c^{T}=c^{\text {annual }} \cdot \frac{T}{(365 \cdot 24 \cdot 3600)}$; where $T$ is the duration of the time interval in seconds; and $c^{\text {annual }}$ is the annual cost rate per $\mathrm{dB}(\mathrm{A})$ that is exposed to one individual. In this study, $c_{\text {annual }}$ is set to $63.3 \mathrm{EUR}$ based on value given in the EWS (FGSV, 1997) for the year 1995, updated with an annual interest rate of $2 \%$ and converted into EUR. A detailed description of the applied noise computation methodology is provided in Kaddoura et al. (2015c) and Kaddoura et al. (2016).

Extension: Actual speed instead of free speed The RLS-90 noise computation approach ignores actual vehicle speeds. Instead, the RLS-90 only accounts for the maximum speed level in the range of 30 to $130 \mathrm{~km} / \mathrm{h}$ for passenger cars and 30 to $80 \mathrm{~km} / \mathrm{h}$ for HGV. In this study, the noise computation methodology is modified in order to account for the

\footnotetext{
${ }^{2}$ In this study, the threshold immission values are set to $50 \mathrm{~dB}(\mathrm{~A})$ for during the day (6 a.m. to 6 p.m.), $45 \mathrm{~dB}(\mathrm{~A})$ for during the evening (6 p.m. to 10 p.m.) and $40 \mathrm{~dB}(\mathrm{~A})$ for the night (10 p.m. to 6 a.m.).
} 
interplay of noise and traffic congestion, i.e. reduced speed levels resulting in lower noise levels. Other than described in the RLS-90, in this study, noise emissions are computed based on the actual speed level instead of the free speed level. Thus, the extended computation approach additionally requires the average speed level of each road segment and time interval which are both provided by the dynamic traffic simulation. For speeds below $30 \mathrm{~km} / \mathrm{h}$, noise levels are computed assuming a minimum speed of $30 \mathrm{~km} / \mathrm{h}$. For speeds above the valid range, the speed level which is used to compute noise emissions is set to either $130 \mathrm{~km} / \mathrm{h}$ for passenger cars or $80 \mathrm{~km} / \mathrm{h}$ for HGV.

\section{Simulation experiments}

In this study, three simulation experiments are carried out. The first two experiments investigate both of the above described pricing approaches separately. The third simulation experiment combines the two pricing approaches and traffic congestion and noise exposures are simultaneously optimized.

1. Isolated congestion pricing: External congestion effects are internalized applying the methodology described in Sec. 2.3.

2. Isolated noise exposure pricing: Noise exposure costs are internalized applying the methodology described in Sec. 2.4. In order to properly account for the interplay of congestion and noise, noise emissions are calculated applying the extension, i.e. using the actual speed level instead of the free speed level. Noise exposure costs are computed assuming that noise damages are incurred for individuals that are exposed to noise at home, at work and education activities, i.e. school and university.

3. Simultaneous congestion and noise exposure pricing: Prices are simultaneously set based on the external noise and congestion cost applying the methodology described in Sec. 2.3 and 2.4. For the computation of noise exposure costs, again, noise damages are assumed to be incurred for individuals at home, work and education activities.

Each simulation experiment is run for a total of 100 iterations. During each of the first 80 iterations, $10 \%$ of the agents experience new routes. During the final 20 iterations, 
agents' choice sets are fixed and travel plans are selected based on a multinomial logit model. Thereby, the number of travel alternatives per agent is limited to 4 plans.

\section{Real world case study}

The above described simulation experiments are applied to the real world case study of the greater Berlin region, Germany. The case study was generated by Neumann et al. (2014) who converted a macroscopic and trip-based model into an activity- and agent-based MATSim scenario. Transport demand comprises survey-based "populationrepresentative" agents and "non-population representative" incorporating additional traffic such as freight and tourist traffic. The scenario was calibrated accounting for the mode shares, travel times and travel distances. As input demand for the above described simulation experiments, the agents' executed plans of the relaxed travel demand generated by Neumann et al. (2014) are used. To allow for a better computational performance, a $10 \%$ population sample is used. Furthermore, the public transport mode is considered applying a simplified approach in which travel times are computed based on the beeline distance. This study focuses on traffic congestion within the road network. Delay effects within the public transport mode or interaction between cars and buses is neglect. The noise computation is limited to noise caused by passenger cars and trucks, other noise sources such as public transit vehicles are not accounted for.

\section{Results and discussion}

\subsection{The interplay of congestion and nosie}

In this section, the extension described in Sec. 2.4 is compared to the existing approach. The extended noise computation approach accounts for reduced speed levels due to traffic congestion. Fig. 1 depicts the changes in noise immissions for the city center area of Berlin between 3.00 and 4.00 p.m. as a result of the new computation approach. For certain road segments, actual speed levels are lower compared to the free speed level which directly translates into lower noise emissions. However, for some road segments traffic congestion is on a very low level resulting in very small differences between the model extension and the existing approach. The differences in noise levels are found to be much larger 


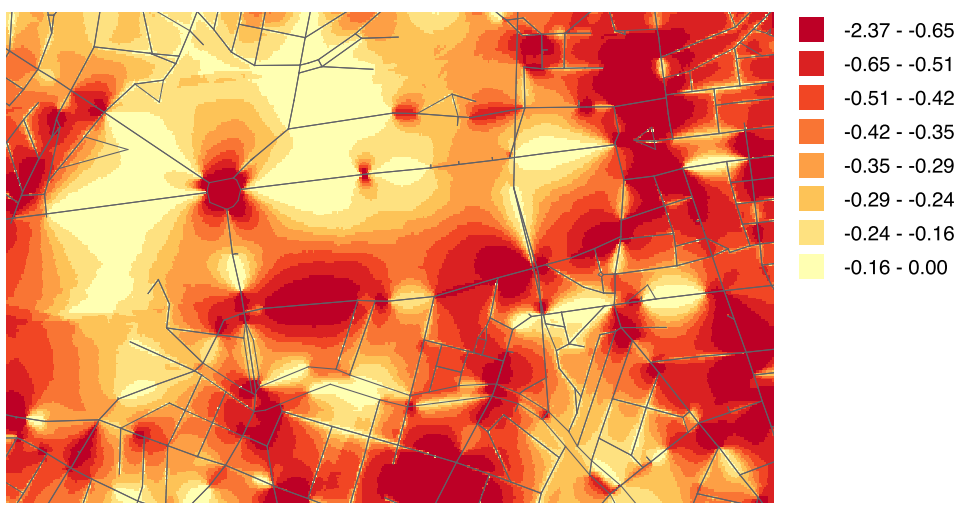

Figure 1: Change in noise levels in $\mathrm{dB}(\mathrm{A})$ as a result of traffic congestion (City center area of Berlin, 3.00 - 4.00 p.m.)

along motorways during peak times. This is explained by the higher free speed level and therefore larger differences between the free speed and the actual speed level in the case of congestion.

\subsection{Simultaneous versus isolated noise and congestion pricing}

\section{Aggregated results}

Tab. 1 provides aggregated results for all pricing experiments. In simulation experiment 1, tolls are set based on marginal external congestion costs, whereas, noise damages are neglected (isolated congestion cost pricing). In simulation experiment 2 tolls are set based on marginal external noise exposure costs, whereas, external congestion costs are not accounted for (isolated noise cost pricing). In experiment 3, the optimization methodology is simultaneously applied to both congestion and noise.

In all pricing experiments, transport users are enabled to adjust their route choice decisions. In order to avoid highly tolled roads, transport users are even willing to take detours. Consequently, the total travel distance is found to increase for all pricing experiments. In the isolated congestion pricing policy (experiment 1), the change in travel behavior results in a congestion relief effect indicated by a decrease in total travel time. In contrast, the isolated noise pricing policy (experiment 2) results in a much larger increase in total travel distance and an increase in total travel time.

The noise damage costs are observed to slightly increase in the isolated congestion pricing 
Table 1: Comparison of simulation experiment 1 (isolated congestion cost pricing), 2 (isolated noise cost pricing) and 3 (simultaneous congestion and noise pricing) with the base case

\begin{tabular}{llll}
\hline & Experiment 1 & Experiment 2 & Experiment 3 \\
\hline \hline Changes in travel distance & $+22,899 \mathrm{~km}$ & $+633,070 \mathrm{~km}$ & $+667,146 \mathrm{~km}$ \\
\hline Changes in travel time & $-17,012$ hours & $+4,486$ hours & $-9,971$ hours \\
\hline \hline Benefits from changes in & $-1,147 \mathrm{EUR}$ & $+110,867 \mathrm{EUR}$ & $+110,413 \mathrm{EUR}$ \\
noise damage costs & & & \\
\hline Changes in travel related & $-1,033,819 \mathrm{EUR}$ & $-373,970 \mathrm{EUR}$ & $-1,507,082 \mathrm{EUR}$ \\
$\begin{array}{llll}\text { user benefits (including toll } \\
\text { payments) }\end{array}$ & & & \\
\hline Changes in toll revenues & $+1,484,971 \mathrm{EUR}$ & $+367,007 \mathrm{EUR}$ & $+1,883,735 \mathrm{EUR}$ \\
\hline \hline Changes in system welfare & $+450,006 \mathrm{EUR}$ & $+103,903 \mathrm{EUR}$ & $+487,066 \mathrm{EUR}$ \\
\hline
\end{tabular}

policy (experiment 1). In contrast, isolated noise pricing (experiment 2) results in a large decrease of noise damage costs.

The system welfare is defined as the sum of the transport users' travel related benefits (including toll payments), the toll revenues and the population's noise damages. Each of the three pricing experiments results in an increase in system welfare. In the simultaneous congestion and noise pricing policy (experiment 3), both the total travel time and noise damage costs are found to decrease. Consequently, the increase in system welfare is larger compared to the isolated pricing studies (experiment 1 or 2 ).

A comparison of the aggregated numbers for simulation experiment 1 and 2 reveals that congestion and noise tolling has an opposite effect. Each isolated pricing policy is found to reduce one external effect but to increase the other one. Therefore, in the simultaneous congestion and noise pricing policy, the increase in system welfare is below the sum of the increase in welfare in the two isolated pricing policies. 


\section{Spatial and temporal analysis}

Fig. 2 depicts the changes in daily traffic volume as a result of the different pricing policies. A comparison of Fig. 2a and 2b illustrates the conflicting route shift effects resulting from congestion and noise tolling.

Isolated congestion pricing results in route shifts from major to minor roads. In particular, transport users avoid the heavily congested and tolled inner-city motorway and use alternative routes along smaller roads (see Fig. 2a). Thereby, the simulation captures the following effects on the noise level:

- Due to the logarithmic computation of noise, a shift from a busy road to a less busy road translates into higher noise levels.

- Overall, the population density along the motorway is rather low, whereas, the population density is much higher along smaller roads. Thus, shifting from less densely populated areas to very densely populated areas increases the level of noise exposures.

- Reduced traffic congestion is linked to a higher speed level which in turn increases the noise level (see Sec. 4.1).

In contrast, isolated noise pricing results in an increase in traffic volume on the inner-city motorway and on main corridors in less densely populated areas. In return, the traffic volume decreases on smaller inner-city roads (see Fig. 2b). This has the following impact on traffic congestion:

- Transport users avoid densely populated areas by taking detours (longer travel distances and travel times) which increases the traffic volume and the congestion level.

- Due to the logarithmic structure of noise, marginal noise cost tolls are lower on very busy roads. As a result, transport users are concentrated along major roads resulting in a higher level of congestion.

Fig. 3 depicts the resulting change in $L_{d e n}$, the day-evening-night noise index proposed by the Environmental Noise Directive of the European Union 2002/49/EC. As indicated by Tab. 1, in the isolated congestion pricing policy (experiment 1), the increase in noise 


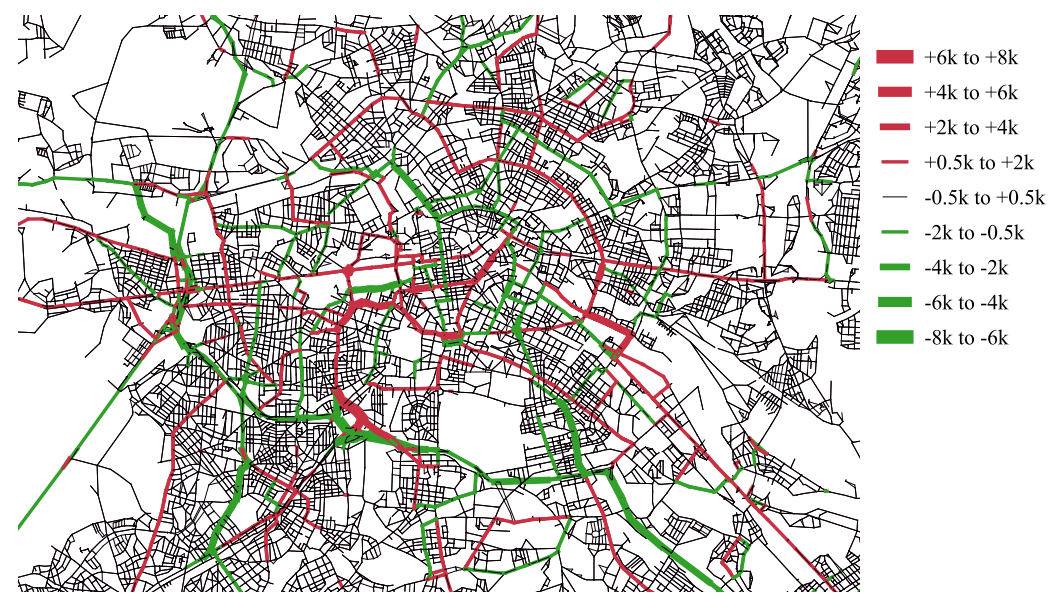

(a) Isolated congestion pricing (Experiment 1)

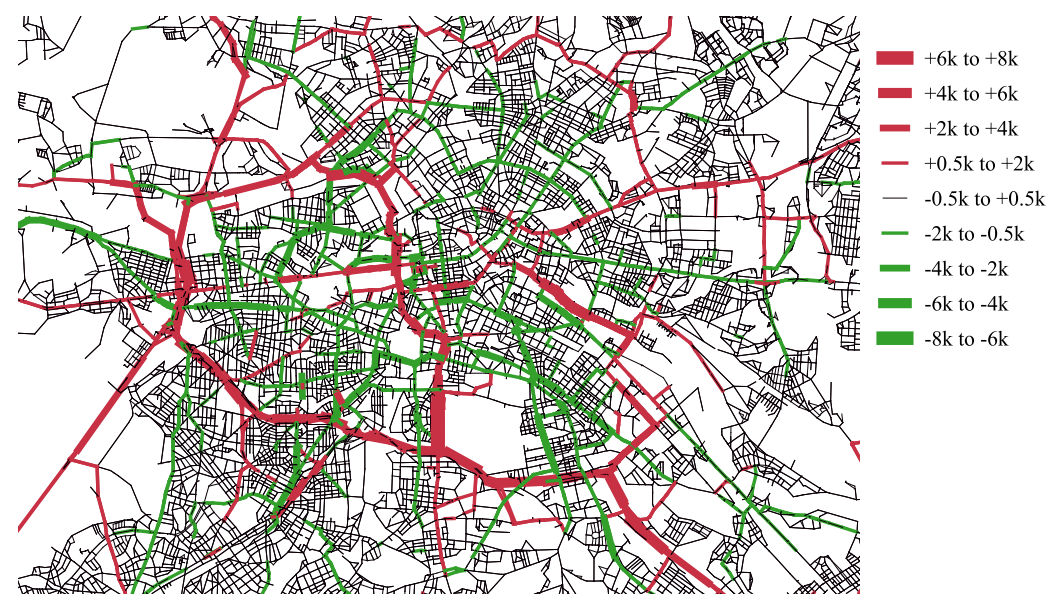

(b) Isolated noise pricing (Experiment 2)

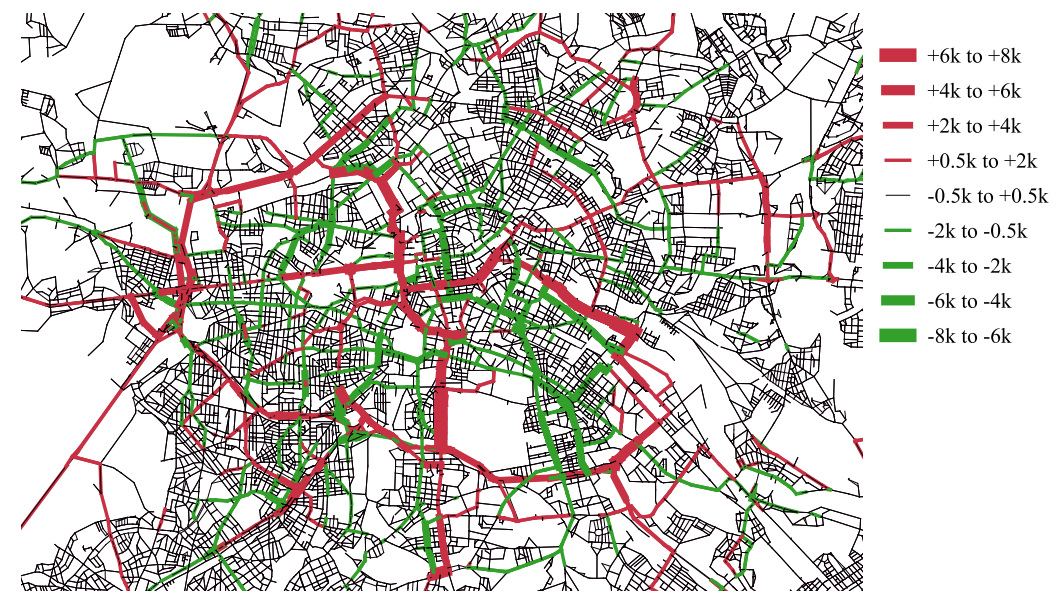

(c) Simultaneous congestion and noise pricing (Experiment 3)

Figure 2: Changes in daily traffic volume

damages is rather small. Fig. 3a reveals a small decrease in noise along certain corridors and a small increase in noise in a wider area. That is, the increase in noise damages is due 


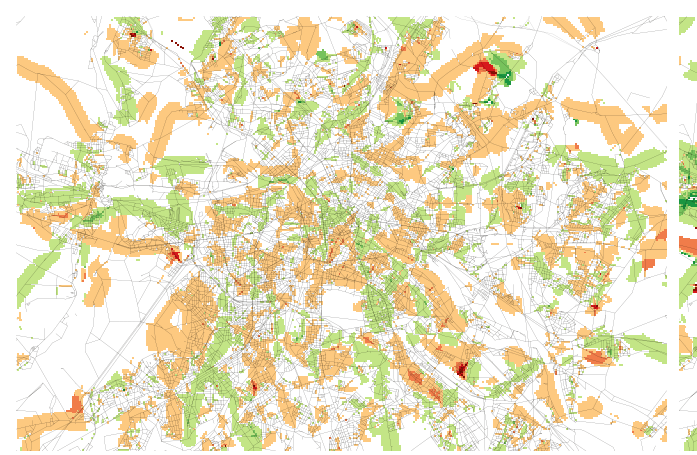

(a) Isolated congestion pricing (experiment 1)

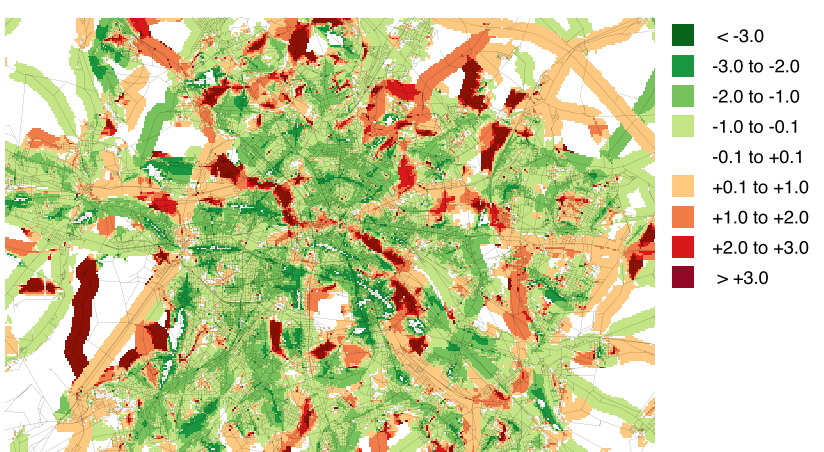

(b) Isolated noise pricing (experiment 2)

Figure 3: Change in noise levels in $\mathrm{dB}(\mathrm{A})$ as a result of the pricing policy $\left(L_{\text {den }}\right.$ : day-evening-night noise index, see Environmental Noise Directive of the European Union 2002/49/EC)

to the larger number of exposed people rather than the increase in noise levels. In contrast, in the isolated noise pricing policy (experiment 2), the increase in noise damages is much larger. Fig. $3 \mathrm{~b}$ reveals that in a very wide area, noise levels are significantly reduced, whereas, along certain corridors with few exposed individuals, noise levels significantly increase.

In the simultaneous congestion and noise pricing policy (experiment 3), the changes in daily traffic volume depicted in Fig. 2c seem to correspond to the overlay of Fig. 2a and $2 \mathrm{~b}$. The resulting changes in traffic volume in experiment 3 is either weakened or strengthened. Moreover, in the simultaneous pricing policy, the change in noise levels is similar to the isolated noise pricing policy (Fig. 3b).

Fig. 4 depicts the average toll per trip departure time for each pricing experiment. The

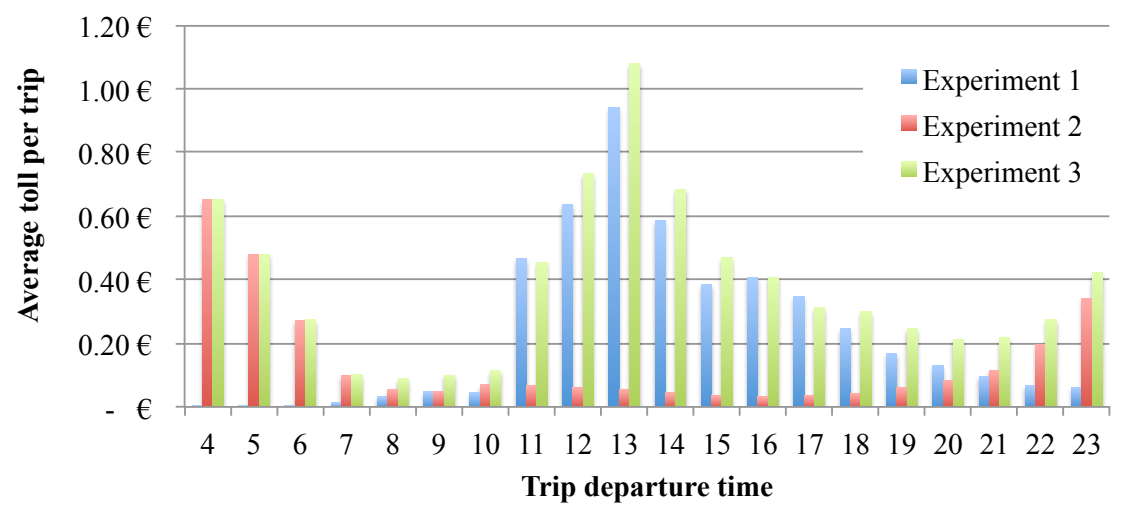

Figure 4: Average toll per trip departure time; Experiment 1: Isolated congestion cost pricing; Experiment 2: Isolated noise cost pricing; Experiment 3: Simultaneous congestion and noise pricing 
isolated congestion pricing study (experiment 1) results in high toll levels during the day and very low toll levels during early morning and late evening. In contrast, the isolated noise pricing study (experiment 2) results in high toll levels during the early morning and late evening. However, during the day, noise limit values are higher and marginal noise costs are lower which both results in lower noise prices. That is, in the simultaneous congestion and noise pricing study (experiment 3), depending on the time of the day, road prices result from different effects. During the day, travel behavior is dominated by the reaction to avoid congestion prices. In contrast, during the early morning and late evening, travel behavior is dominated by the reaction to avoid noise prices.

Fig. 5 depicts the changes in traffic volume as a result of the simultaneous congestion and noise pricing policy for a time period during the day (3 p.m. -4 p.m.) and for an off-peak time period (8 p.m.-9 p.m.). As indicated by Fig. 4 , a comparison of Fig. $5 \mathrm{a}$ and Fig. $5 \mathrm{~b}$ reveals different route shift effects for different times of the day. During the afternoon peak, the changes in traffic volume are similar to the isolated congestion pricing policy, i.e. transport users are observed to shift from major to minor roads. In contrast, in the evening, the demand changes are similar to the isolated noise pricing, i.e. transport users are observed to shift from minor to major roads.

\section{Conclusion}

This study elaborates on the interrelation of external effects. For congestion and noise, single objective optimization is compared with multiple objective optimization. The optimization methodology follows an iterative market-based approach. An agent-based simulation framework is used to compute and internalize external congestion effects and noise exposures. The applied internalization approach accounts for dynamic congestion and heterogeneous values of travel time savings. Optimal tolls are dynamically computed for each transport user and road segment. For the case study of the Greater Berlin area, three simulation experiments are carried out, (1) isolated congestion pricing, (2) isolated noise pricing and (3) simultaneous congestion and noise pricing. In each pricing experiment, transport users are enabled to adjust their rout choice decisions in order to avoid toll payments.

The results reveal a negative correlation between congestion and noise since the internal- 


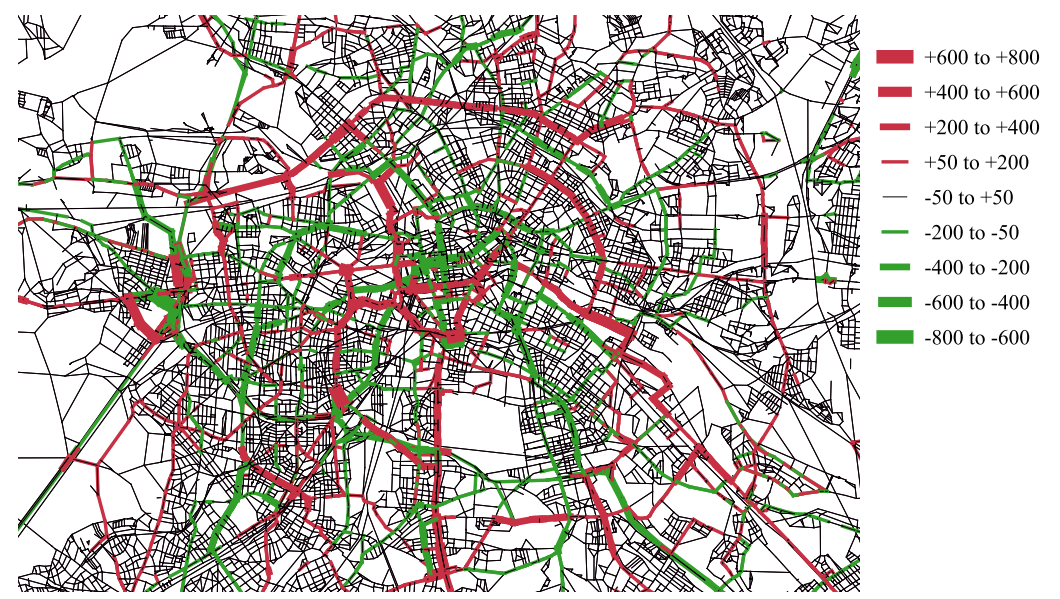

(a) Peak: 3 p.m. -4 p.m.

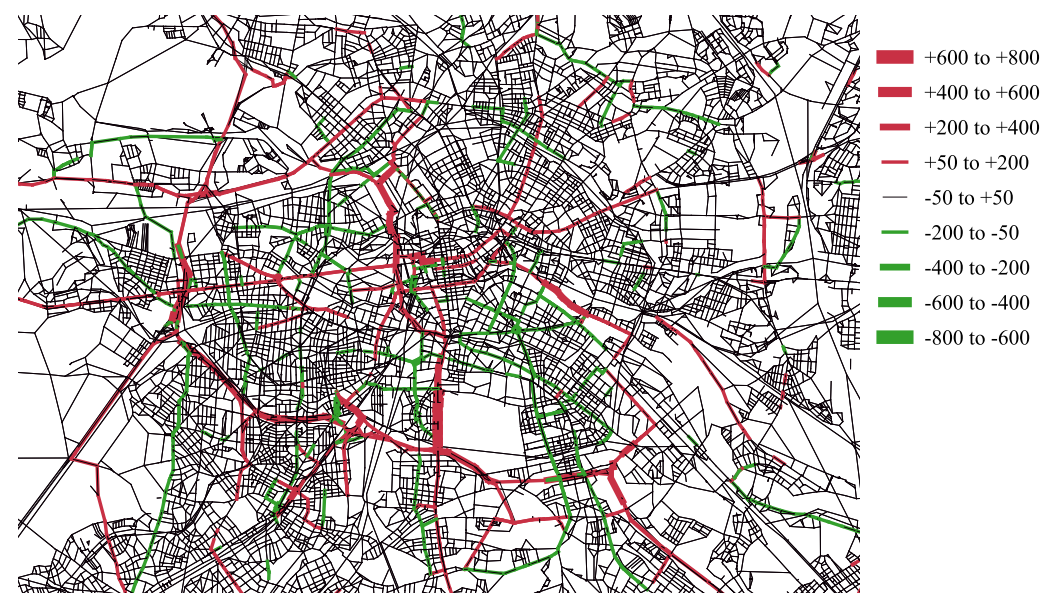

(b) Off-peak: 8 p.m.-9 p.m.

Figure 5: Changes in traffic volume: Simultaneous congestion and noise pricing (Experiment 3)

ization of one effect increases the other one. This interrelation of congestion and noise is consistent with the findings of other studies (Wismans et al., 2011; Makarewicz and Galuszka, 2011, see Sec. 11. Nevertheless, the multiple objective optimization shows that it is possible to simultaneously reduce congestion costs and noise damages. Going beyond the scope of most existing studies, the results are analyzed for a large-scale network and a detailed representation of the population. A detailed investigation of temporal and spatial effects reveals that the interrelation of congestion and noise is very low. Depending on the time of day, travel behavior primarily results from avoiding either one externality or the other one. During peak times, congestion is the more relevant external effect, whereas, during off-peak times, in particular during the night, noise is the more relevant externality. During peak times, transport users are observed to shift from the inner-city motorway to 
smaller roads. In contrast, during off-peak times, transport users shift from minor to main roads, in particular to the inner-city motorway.

The presented methodology provides important implications for policy makers. The results of the Berlin case study indicate that it is possible to simultaneously reduce congestion and noise. The key factor is to follow a dynamic traffic management approach and temporally change the incentives during the course of the day. During the day, transport policies should rather be targeted at avoiding congestion, i.e. by motivating a shift from congested motorways to smaller roads and spreading the demand within the network. Due to lower noise limit values during the day compared to the morning, evening and night, the increase in noise damage costs is minor compared to the reduction in congestion costs. In contrast, during off-peak times, in particular during the evening, night and morning, transport policies should rather aim at reducing noise exposures. This objective may be achieved by concentrating traffic flows or providing incentives to use roads in less densely populated areas. The through traffic may for example be banned in residential areas inducing transport users to take detours. The resulting increase in traffic congestion seems minor compared to the reduction in noise exposures.

The presented methodology may easily be applied to further case studies to investigate whether the policy recommendations hold for a different spatial and temporal structure of the transport system and the population. In future studies, the proposed market-based optimization approach will be extended to simultaneously account for further external effects such as air pollution (Kickhöfer and Kern, 2015) and accidents. In the applied case study of the Greater Berlin area, transport users are only enabled to adjust their transport routes. However, the presented optimization methodology allows for more complex user reactions. Transport users may for example be enabled to adjust their mode of transportation. In this context, the presented methodology may be combined with existing optimization approaches for the public transport mode (Kaddoura et al., 2015a b). 


\section{References}

2002/49/EC. Directive of the European Parliament and of the Council of 25 June 2002 relating to the assessment and management of environmental noise. Official Journal of the European Communities.

Agarwal, A. and B. Kickhöfer. Agent-based simultaneous optimization of congestion and air pollution: A real-world case study. Procedia Computer Science, 52(C):914-919, 2015. ISSN 1877-0509. doi: $10.1016 /$ j.procs.2015.05.165.

Agarwal, A., M. Zilske, K. Rao, and K. Nagel. An elegant and computationally efficient approach for heterogeneous traffic modelling using agent based simulation. Procedia Computer Science, 52(C):962-967, 2015. ISSN 1877-0509. doi: 10.1016/j.procs.2015.05.173.

Barth, M. and K. Boriboonsomsin. Traffic congestion and greenhouse gases. ACCESS Magazine, University of California Transportation Center, 35, 2009.

Beamon, B. M. and P. M. Griffin. A simulation-Based methodology for analyzing congestion and emissions on a transportation network. Simulation, 72(2):105-114, 1999. doi: 10.1177/ 003754979907200204 .

Beevers, S. D. and D. C. Carslaw. The impact of congestion charging on vehicle emissions in London. Atmospheric Environment, 39:1-5, 2005. doi: 10.1016/j.atmosenv.2004.10.001.

Calthrop, E. and S. Proost. Road Transport Externalities. Environmental and Resource Economics, 11(3-4):335-348, 1998. doi: 10.1023/A:1008267917001. URL http://dx.doi.org/10.1023/A\% 3A1008267917001.

Charypar, D. and K. Nagel. Generating complete all-day activity plans with genetic algorithms. Transportation, 32(4):369-397, 2005. ISSN 0049-4488. doi: 10.1007/s11116-004-8287-y.

Chen, L. and H. Yang. Managing congestion and emissions in road networks with tolls and rebates. Transportation Research Part B: Methodological, 46:933-948, 2012. doi: 10.1016/j.trb.2012.03. 001.

Daniel, J. I. and K. Bekka. The environmental impact of highway congestion pricing. Journal of Urban Economics, 47:180-215, 2000. doi: 10.1006/juec.1999.2135.

de Borger, B., I. Mayeres, S. Proost, and S. Wouters. Optimal pricing of urban passenger transport: A simulation exercise for Belgium. Journal of Transport Economics and Policy, 30(1):31-54, 1996. 
FGSV. Richtlinien für den Lärmschutz an Straßen (RLS), Ausgabe 1990, Berichtigte Fassung. Forschungsgesellschaft für Straßen- und Verkehrswesen, 1992. URL http://www.fgsv.de.

FGSV. Empfehlungen für Wirtschaftlichkeitsuntersuchungen an Straßen (EWS). Aktualisierung der RAS-W 86. Forschungsgesellschaft für Straßen- und Verkehrswesen, 1997. URL http: //www.fgsv.de.

Gawron, C. An Iterative Algorithm to Determine the Dynamic User Equilibrium in a Traffic Simulation Model. International Journal of Modern Physics C, 9(3):393-407, 1998.

Ghafghazi, G. and M. Hatzopoulou. Simulating the environmental effects of isolated and area-wide traffic calming schemes using traffic simulation and microscopic emission modeling. Transportation, 41:633-649, February 2014.

High Level Group on Transport Infrastructure Charging. Calculating Transport Accident Costs. Final report of the expert advisors to the high level group on infrastructure charging, 1999. URL http://ec.europa.eu/transport/infrastructure/doc/crash-cost.pdf. See http:// ec.europa.eu/transport/infrastructure/doc/crash-cost.pdf.

Kaddoura, I. Marginal Congestion Cost Pricing in a Multi-Agent Simulation: Investigation of the Greater Berlin Area. Journal of Transport Economics and Policy, 49(4):560-578, 2015.

Kaddoura, I. and B. Kickhöfer. Optimal Road Pricing: Towards an Agent-based Marginal Social Cost Approach. VSP Working Paper 14-01, TU Berlin, Transport Systems Planning and Transport Telematics, 2014. See http://www.vsp.tu-berlin.de/publications.

Kaddoura, I. and K. Nagel. Activity-based computation of marginal noise exposure costs: Impacts for traffic management. Annual Meeting Preprint 16-3437, Transportation Research Board, Washington D.C., January 2016a. Also VSP WP 15-13, see http://www.vsp.tu-berlin.de/ publications

Kaddoura, I. and K. Nagel. Agent-based congestion pricing and transport routing with heterogeneous values of travel time savings. VSP Working Paper 16-01, TU Berlin, Transport Systems Planning and Transport Telematics, 2016b.

Kaddoura, I., B. Kickhöfer, A. Neumann, and A. Tirachini. Agent-based optimisation of public transport supply and pricing: Impacts of activity scheduling decisions and simulation randomness. Transportation, 42(6):1039-1061, 2015a. ISSN 0049-4488. doi: 10.1007/s11116-014-9533-6.

Kaddoura, I., B. Kickhöfer, A. Neumann, and A. Tirachini. Optimal public transport pricing: Towards an agent-based marginal social cost approach. Journal of Transport Economics 
and Policy, 49(2):200-218, 2015b. Also VSP WP 13-09, see http://www.vsp.tu-berlin.de/ publications. Awarded as the Best PhD Student Paper at hEART 2013.

Kaddoura, I., L. Kröger, and K. Nagel. An activity-based and dynamic approach to calculate road traffic noise damages. VSP Working Paper 15-05, TU Berlin, Transport Systems Planning and Transport Telematics, 2015c.

Kaddoura, I., L. Kröger, and K. Nagel. User-specific and dynamic internalization of road traffic noise exposures. Networks and Spatial Economics, 2016. doi: 10.1007/s11067-016-9321-2. Also VSP WP 15-12, see http://www.vsp.tu-berlin.de/publications.

Kickhöfer, B. and J. Kern. Pricing local emission exposure of road traffic: An agent-based approach. Transportation Research Part D: Transport and Environment, 37(1):14-28, 2015. ISSN 13619209. doi: 10.1016/j.trd.2015.04.019.

Kickhöfer, B., F. Hülsmann, R. Gerike, and K. Nagel. Rising car user costs: comparing aggregated and geo-spatial impacts on travel demand and air pollutant emissions. In Vanoutrive, T. and A. Verhetsel, editors, Smart Transport Networks: Decision Making, Sustainability and Market structure, NECTAR Series on Transportation and Communications Networks Research, pages 180-207. Edward Elgar Publishing Ltd, 2013. ISBN 978-1-78254-832-4.

Korzhenevych, A., N. Dehnen, J. Bröcker, M. Holtkamp, H. Meier, G. Gibson, A. Varma, and V. Cox. Update of the Handbook on External Costs of Transport. Technical report, European Commission - DG Mobility and Transport, 2014.

Maibach, M., D. Schreyer, D. Sutter, H. van Essen, B. Boon, R. Smokers, A. Schroten, C. Doll, B. Pawlowska, and M. Bak. Handbook on estimation of external costs in the transport sector. Technical report, CE Delft, 2008. URL http://ec.europa.eu/transport/sustainable/ doc/2008_costs_handbook.pdf. Internalisation Measures and Policies for All external Cost of Transport (IMPACT).

Makarewicz, R. and M. Galuszka. Road traffic noise prediction based on speed-flow diagram. Applied Acoustics, 72(4):190-195, 2011.

Nagel, K. and G. Flötteröd. Agent-based traffic assignment: Going from trips to behavioural travelers. In Pendyala, R. and C. Bhat, editors, Travel Behaviour Research in an Evolving World - Selected papers from the 12th international conference on travel behaviour research, chapter 12, pages 261-294. International Association for Travel Behaviour Research, 2012. ISBN 978-1-105-47378-4.

Nash, C. UNIfication of accounts and marginal costs for Transport Efficiency (UNITE). Final Report for Publication, Funded by 5th Framework RTD Programme, 2003. 
Neumann, A., M. Balmer, and M. Rieser. Converting a Static Trip-Based Model Into a Dynamic Activity-Based Model to Analyze Public Transport Demand in Berlin. In Roorda, M. and E. Miller, editors, Travel Behaviour Research: Current Foundations, Future Prospects, chapter 7, pages 151-176. International Association for Travel Behaviour Research (IATBR), 2014. ISBN 9781304715173.

Noland, R., M. Quddus, and W. Ochieng. The effect of the London congestion charge on road casualties: an intervention analysis. Transportation, 35(1):73-91, 2008. ISSN 0049-4488. doi: 10.1007/s11116-007-9133-9.

Parry, I. W. H. and K. A. Small. Should urban transit subsidies be reduced? American Economic Review, 99:700-724, 2009.

Percoco, M. The effect of road pricing on traffic composition: Evidence from a natural experiment in Milan, Italy. Transport Policy, 31(0):55-60, 2014. ISSN 0967-070X. doi: 10.1016/j.tranpol. 2013.12.001.

Percoco, M. Heterogeneity in the reaction of traffic flows to road pricing: a synthetic control approach applied to Milan. Transportation, 42(6):1063-1079, 2015. ISSN 0049-4488. doi: 10.1007/s11116-014-9544-3.

Pigou, A. The Economics of Welfare. MacMillan, New York, 1920.

Proost, S. and K. van Dender. The welfare impacts of alternative policies to address atmospheric pollution in urban road transport. Regional Science and Urban Economics, 31(4):383-411, 2001. ISSN 0166-0462. doi: 10.1016/S0166-0462(00)00079-X.

Raney, B. and K. Nagel. An improved framework for large-scale multi-agent simulations of travel behaviour. In Rietveld, P., B. Jourquin, and K. Westin, editors, Towards better performing European Transportation Systems, pages 305-347. Routledge, London, 2006.

Shefer, D. and P. Rietveld. Congestion and Safety on Highways: Towards an Analytical Model. Urban Studies, 34(4):679-692, 1997.

Shepherd, S. P. The effect of complex models of externalities on estimated optimal tolls. Transportation, 35(4):559-577, 2008. ISSN 0049-4488. doi: 10.1007/s11116-007-9157-1.

Small, K. A. and E. T. Verhoef. The economics of urban transportation. Routledge, 2007. ISBN 9780415285148.

Verhoef, E. T. and J. Rouwendal. A Structural Model of Traffic Congestion: Endogenizing speed choice, traffic safety and time losses. Technical report, Department of Spatial Economics, Free University Amsterdam, 2003. 
Wang, J., L. Chi, X. Hu, and H. Zhou. Urban traffic congestion pricing model with the consideration of carbon emissions cost. Sustainability, 6(2):676-691, 2014. doi: 10.3390/su6020676.

Wismans, L., E. van Berkum, and M. Bliemer. Dynamic Traffic Management Measures to Optimize Air Quality, Climate, Noise, Traffic Safety and Congestion: Effects of a Single Objective Optimization. In van Nunen, J. A., P. Huijbregts, and P. Rietveld, editors, Transitions Towards Sustainable Mobility, pages 297-313. Springer Berlin Heidelberg, 2011. doi: 10.1007/978-3-642-21192-8\-16. 